\title{
Cold storage affects mortality, body mass, lifespan, reproduction and flight capacity of Praon volucre (Hymenoptera: Braconidae)
}

\author{
Juracy Caldeira Lins, JR ${ }^{1}$, Vanda Helena Paes BuenO ${ }^{1 *}$, Livia Alvarenga SidneY ${ }^{1}$, Diego Bastos Silva ${ }^{1}$, \\ Marcus Vinicius SAMPAIO ${ }^{2}$, Janser Moura PEREIRA $^{3}$, Quintiliano Siqueira Schroden NOMELINI ${ }^{3}$ \\ and JOOP C. VAN LENTEREN ${ }^{4}$ \\ ${ }^{1}$ Department of Entomology, Federal University of Lavras, CP 3037, MG 37200-000, Lavras, Brazil; e-mails: \\ juracylins@yahoo.com.br; vhpbueno@den.ufla.br; liviasidney@yahoo.com.br; \\ ${ }^{2}$ Agricultural Sciences Institute, Federal University of Uberlandia, MG 38400-902, Uberlandia, Brazil; \\ e-mail: mvsampaio@iciag.ufu.br \\ ${ }^{3}$ Faculty of Mathematics, Federal University of Uberlandia, MG 38408-100, Uberlandia, Brazil \\ ${ }^{4}$ Laboratory of Entomology, Wageningen University, Wageningen, The Netherlands; e-mail: Joop.vanLenteren@wur.nl
}

Key words. Hymenoptera, Braconidae, Praon volucre, parasitoid quality, biological control, storage, Macrosiphum euphorbiae

\begin{abstract}
The possibility of storing natural enemies at low temperatures is important for the mass production of biological control agents. We evaluated the effect of different periods of cold storage on immature mortality, mummy body mass, lifespan, reproduction and flight capacity of the parasitoid Praon volucre (Haliday). One-day-old mummies of the aphid Macrosiphum euphorbiae (Thomas) containing pre-pupae of $P$. volucre were stored in a climatic chamber at $5^{\circ} \mathrm{C}$ and $70 \pm 10 \% \mathrm{RH}$ in the dark for different periods of time $\left(5,10,15\right.$ and 20 days). The control consisted of mummies kept at $22 \pm 1{ }^{\circ} \mathrm{C}, 70 \pm 10 \% \mathrm{RH}$ and a $12 \mathrm{~h}$ photophase. Percentage adult emergence, mummy body mass, flight capacity and number of eggs in the ovarioles of $P$. volucre females decreased with increase in the period of storage, while the longevity of females was only slightly affected. Fat content of mummies, percentage of parasitized aphids and survival of progeny to emergence decreased with increase in the period of storage. Storage of $P$. volucre pre-pupae for up to 5 days at $5^{\circ} \mathrm{C}$ did not affect any of the above mentioned parameters. The fact that $P$. volucre pre-pupae can be stored for 5 days without loss of quality and for 10 days with only a slight loss facilitates the planning of mass production and shipment.
\end{abstract}

\section{INTRODUCTION}

Insect storage at low temperatures can be an important and valuable tool in the mass production of entomophagous biological control agents (van Lenteren \& Tommasini, 2003). Low temperature storage allows greater flexibility in the production and shipment, and facilitates the synchronization of the production in the laboratory with the timing of release in the field (Leopold, 1998; Colinet \& Boivin, 2011). Most studies show that the optimum temperature for storage of parasitoids is between $0^{\circ}$ and $7^{\circ} \mathrm{C}$ (e.g. Hofsvang \& Hågvar, 1977; Singh \& Srivastava, 1988; Rodrigues et al., 2003; Colinet et al., 2006, 2007). In cold storage insects enter a dormant state known as quiescence, resulting in a slowdown of their metabolic activities in response to the adverse environmental conditions. When removed from storage they develop and behave normally (Leopold, 1998).

Although storage at low temperatures seems an attractive option, the results are often disappointing (van Lenteren \& Tommasini, 2003). Low temperature storage can directly influence important biological parameters of insects (Denlinger \& Lee, 1998). In the specific case of aphid parasitoids, prolonged storage at low temperatures are associated with poor immature survival (Hofsvang \&
Hågvar, 1977), reduced adult longevity (Colinet et al., 2006) and reproduction (Levie et al., 2005; Bourdais et al., 2012), and poor flight capacity (van Lenteren et al., 2003) and adult performance (Amice et al., 2008). In order to improve mass rearing and release of natural enemies, knowledge of the relationship between storage time, temperature and performance of biological control agents is of paramount importance (Tezze \& Botto, 2004; Colinet \& Boivin, 2011). In this paper we determined this relationship for the parasitoid Praon volucre (Haliday) (Hymenoptera: Braconidae). There are several papers on different aspects of the effects of storage on Braconid parasitoids, but this study considers the whole range of parameters including the effect on flight capacity.

Praon volucre is a solitary endoparasitoid originating from the Palaearctic region, which has spread to several other regions (e.g., South America and Oceania), and has a large host range (Carver \& Woolcock, 1986; Starý et al., 2007). According to Tomanović et al. (2009), $P$. volucre is associated with 24 species of aphids in commercial crops in Europe and with several other aphid species on weeds. This parasitoid occurs in several regions of Brazil, attacking aphids on ornamental plants, alfalfa and pea crops, and native grasses (Gassen \& Tambasco, 1983). Praon volucre is considered to be an important

\footnotetext{
* Corresponding author.
} 
natural enemy of aphids of the tribe Macrosiphini (Hemiptera: Aphididae) (Starý et al., 2007), such as Macrosiphum euphorbiae (Thomas) (De Conti et al., 2011; Lins et al., 2011), Uroleucon ambrosiae (Tomas) (De Conti et al., 2008) and Aulacorthum solani (Kaltenbach) (Silva et al., 2009), and has been commercially produced as an aphid natural enemy in Europe since the 1990s (van Lenteren, 2012). Colinet \& Hance (2010) found that $P$. volucre is moderately tolerant of storage at low temperatures and is not normally seriously injured by low temperature if stored for short periods. However, there are no studies assessing the fitness of this species after storage.

The objective of this study was to evaluate the effect of different periods of storage at a low temperature on immature survival, mummy body mass, reproduction, life span and flight capacity of the parasitoid P. volucre.

\section{MATERIAL AND METHODS}

\section{Rearing M. euphorbiae and $P$. volucre}

M. euphorbiae were collected from lettuce (Lactuca sativa L., $\mathrm{cv}$ Verônica) growing in a greenhouse on the campus of the Federal University of Lavras (UFLA). After identification using the key of Peña-Martinez (1992), aphids were transferred to Petri dishes (15 cm diameter) containing a disc of lettuce leaf, cv. Verônica, on a layer of agar (1\% agar in water). The Petri dishes were kept in a climatic chamber at $22 \pm 1{ }^{\circ} \mathrm{C}, 70 \pm 10 \%$ $\mathrm{RH}$ and a $12 \mathrm{~h}$ photophase. Offspring of the third laboratory generation were used to start a culture of $M$. euphorbiae on potted lettuce plants kept in acrylic cages $(60 \times 30 \times 30 \mathrm{~cm})$, following the methodology of De Conti et al. (2010) and Sidney et al. (2010), which were used for rearing the parasitoid.

Sowthistle plants, Sonchus oleraceus L., infested with colonies of Uroleucon sp. (Hemiptera: Aphididae) in which there were parasitoid mummies were collected from the field in 2008 at Lavras, Minas Gerais state (Brazil) (latitude $21^{\circ} 13^{\prime} 43^{\prime \prime} \mathrm{S}$, longitude $44^{\circ} 58^{\prime} 38^{\prime \prime} \mathrm{W}$, altitude $918 \mathrm{~m}$ ) and maintained in the laboratory until the adult parasitoids emerged. Parasitoids were identified using the diagnostic characteristics cited by Tomanović et al. (2003). Adult $P$. volucre were released on lettuce plants infested with $M$. euphorbiae in acrylic cages $(60 \times 30 \times 30 \mathrm{~cm})$. The sixth laboratory generation of the parasitoids was used in the experiments.

\section{Collection of parasitoid mummies}

$P$. volucre females up to $24 \mathrm{~h}$-old and previously mated and fed mixed-flower honey, were released in Petri dishes $(5 \mathrm{~cm}$ diameter) each containing nymphs of $M$. euphorbiae on a disc of lettuce leaf on a layer of $1 \%$ water-agar in the bottom of the dish. To standardize nymph age, adults of $M$. euphorbiae were kept for $24 \mathrm{~h}$ in Petri dishes (15 cm diameter) containing a disc of lettuce leaf, after which, the adult aphids were removed. A mixture of second and third instar nymphs were used in the experiments. Parasitoids were allowed to parasitize nymphs for a period of two hours. Then, the Petri dishes were each sealed with a paper kitchen towel and kept in a climatic chamber at 22 $\pm 1{ }^{\circ} \mathrm{C}, 70 \pm 10 \% \mathrm{RH}$ and a $12 \mathrm{~h}$ photophase, until mummification (= visible parasitism) of the aphids. Completely developed, one-day-old mummies were used in the storage tests. A total of 1890 mummies were used: 500 to determine mummy body mass and 1390 to determine immature survival, adult longevity, flight capacity, potential fecundity and reproduction of $P$. volucre.

\section{Thermal treatment}

The effect of four storage periods, 5, 10, 15 and 20 days, on mummies stored in the dark in a climatic chamber at $5^{\circ} \mathrm{C}$ and 70 $\pm 10 \% \mathrm{RH}$ was evaluated. We used $5^{\circ} \mathrm{C}$ because De Conti et al. (2011) found that the temperature threshold for development of $P$. volucre is $5.17^{\circ} \mathrm{C}$. The control consisted of mummies maintained at $22 \pm 1{ }^{\circ} \mathrm{C}, 70 \pm 10 \% \mathrm{RH}$ and a $12 \mathrm{~h}$ photophase. To avoid thermal shock when mummies were transferred to the low temperature, they were acclimatized using a modified version of Levie et al. (2005) method: the temperature in the climatic chamber was decreased by $1^{\circ} \mathrm{C}$ every $25 \mathrm{~min}$, until it was $5^{\circ} \mathrm{C}$, which resulted in $425 \mathrm{~min}$ of acclimatization. After the storage period a reverse acclimatization procedure was followed in which the temperature in the climatic chamber was increased by $1^{\circ} \mathrm{C}$ every $25 \mathrm{~min}$, until it reached $22^{\circ} \mathrm{C}$.

\section{Evaluation of mummy body mass loss}

For the evaluation of the loss of body mass by $P$. volucre, 100 mummies, divided into five replicates of 20 , were used for each storage period and for the control. The groups of 20 mummies were weighed on a precision balance $(0.1 \mathrm{mg})$ (Shimadzu AW220, Shimadzu Corporation, Japan) before and after each storage period and similarly for the control, using a modified version of Colinet et al. (2006) method. The loss of body mass during storage was determined by the difference in fresh mass after (FMa) and before (FMb) storage. Next, the mummies were dried in an oven with forced air circulation at $60^{\circ} \mathrm{C}$ for 3 days, then weighed again to determine their dry mass (DM). After this, the lean dry mass (LDM) of mummies was measured after extraction of lipids in a chloroform/methanol $(2: 1)$ solution. To do this each mummy was pierced with a pin and placed in an Eppendorf tube containing $1.5 \mathrm{ml}$ of chloroform/methanol solution for two weeks and shaken daily. Mummies were then placed for $12 \mathrm{~h}$ in a drying oven at $60^{\circ} \mathrm{C}$ to evaporate off the extraction solution and weighed again. The body fat mass (FM) is the difference between the dry mass (DM) and lean dry mass (LDM) $(\mathrm{FM}=\mathrm{DM}-\mathrm{LDM})$, and the relative fat content (FC) is the body fat mass (FM) divided by the dry lean mass (LDM) $(\mathrm{FC}=\mathrm{FM} / \mathrm{LDM})$. The water mass $(\mathrm{WM})$ was the difference between the fresh mass before storage and dry mass (WM = $\mathrm{FMb}-\mathrm{DM})$.

\section{Adult emergence, size and longevity of $\boldsymbol{P}$. volucre}

To determine the effect of storage on adult emergence, mummies were kept at each storage period $(5,10,15$ and 20 days) at $5^{\circ} \mathrm{C}$ in the dark. After the storage period, mummies were placed individually in glass tubes $(100 \times 8 \mathrm{~mm})$ sealed with plastic film until the adult parasitoid emerged. One hundred and ninety mummies were used in the control treatment and tree hundred mummies for each of the storage period treatments.

Length of the right hind tibia was used as a measure of the size of the parasitoid. The tibiae of ten males and ten females that emerged following each storage period were removed and placed in a drop of $70 \%$ alcohol on a microscope slide, covered with a cover slip and measured with the aid of an ocular micrometer scale at $100 \times$ magnification. To assess the longevity of $P$. volucre, 20 newly emerged adults (10 females and 10 males) for each storage period and the control treatments were kept in glass tubes $(100 \times 8 \mathrm{~mm})$ in a climatic chamber at $22 \pm$ $1{ }^{\circ} \mathrm{C}, 70 \pm 10 \% \mathrm{RH}$ and a $12 \mathrm{~h}$ photophase, and fed daily with droplets of water and honey until they died. The other parasitoids that emerged were used for determining flight capacity, potential fecundity and reproduction.

\section{Flight capacity of $P$. volucre}

Flight capacity was tested using a method similar to that described by van Lenteren et al. (2003) and Langer et al. (2004). One-day-old males and females of $P$. volucre from each of the storage period and control treatments were fed honey and then placed in an acrylic tube $(3.5 \times 2 \mathrm{~cm})$, which was put in an open 
Petri dish (15 cm diameter). The open Petri dish formed the bottom of a cylinder. The cylinder had opaque walls, was $20 \mathrm{~cm}$ high and had a diameter of $10 \mathrm{~cm}$. The top of the cylinder had a transparent cover with a layer of glue on the underside. A lamp (cool white light, Philips MASTER PL-S 9W/840/2P 1CT, Koninklijke Philips Electronics N.V.) was placed $10 \mathrm{~cm}$ above of the cylinder to attract the parasitoids. The light intensity was 7600 lux at the site where the parasitoids were placed in the cylinder. To prevent the parasitoids walking to the top of the cylinder the acrylic tube with the parasitoids in the centre of Petri dish was surrounded by water. The number of parasitoids stuck to the underside of the cover at the top of the cylinder was recorded after $4 \mathrm{~h}$. Tests were conducted in a climatic room (22 $\pm 3^{\circ} \mathrm{C}, 70 \% \mathrm{RH}$ ) with 10 parasitoids ( 5 females and 5 males) per test and replicated five times for each storage period and the control treatment.

\section{Potential fecundity and reproduction}

Ten 24 h-old $P$. volucre females that emerged from mummies after storage for different periods at the low temperature and in the control treatment were killed in $70 \%$ ethanol and dissected, and the number of eggs in their ovarioles counted. First, the ovarioles were separated from the remainder of the gaster under a stereomicroscope and then stained with lactophenol blue solution to make the eggs more visible. Next, the eggs in the two ovarioles were counted under a microscope $(100 \times)$ (Sampaio et al., 2008).

To determine the reproductive potential of the $P$. volucre, males and females that emerged after each of the storage periods and in the control treatment they were fed with honey and allowed to mate. Next, each female was released into a Petri dish (5 cm diameter) containing a disc of lettuce leaf infested with a mixture of $20 \mathrm{~s}$ and third instars nymphs of $M$. euphorbiae on the surface of a layer of $1 \%$ water-agar at the bottom of the dish. The parasitoid females remained in the Petri dishes for one hour. After this period, the females were removed from the Petri dishes, kept in glass tubes $(100 \times 8 \mathrm{~mm})$ in a climatic chamber at $22 \pm 1{ }^{\circ} \mathrm{C}, 70 \pm 10 \% \mathrm{RH}$ and a12 $\mathrm{h}$ photophase, and fed daily with droplets of water and honey until tested again. The females were tested in this way when they were 24,48 and $72 \mathrm{~h}$-old. Ten females from each storage period treatment were tested. Ten days after parasitism, mummies were placed individually in glass tubes $(100 \times 8 \mathrm{~mm})$ until the parasitoids emerged. The percentage parasitism and emergence, and sex ratio of the offspring were determined. Superparasitism was not evaluated, because in a previous study we showed that $P$. volucre is well able to discriminate between parasitized and unparasitized M. euphorbiae (Lins et al., 2011).

\section{Data analysis}

For all statistical procedures we used software R 2.10.1 (R Development Core Team, 2008). Initially the data were subjected to an exploratory analysis to verify the residual normality (Shapiro-Wilk test). Then the data were tested for residual homogeneity using the Barlett test (data with a normal distribution) or the Levene test (data that is not normally distributed) and residual independence of the data using the Durbin and Watson test (Gujarati, 2004). We used a 0.01 level of significance for the exploratory analysis. Data with residuals that were not normally distributed and/or heteroscedastic (fraction of adult emergence and number of eggs in ovarioles) were analyzed using Generalized Linear Models (Nelder \& Wedderburn, 1972; McCullagh \& Nelder, 1989; Lee et al., 2006). The fraction that emerged as adults was adjusted to a binomial distribution with a logistic link function, and the number of eggs in ovarioles adjusted to a Poisson distribution using a logarithmic link func-

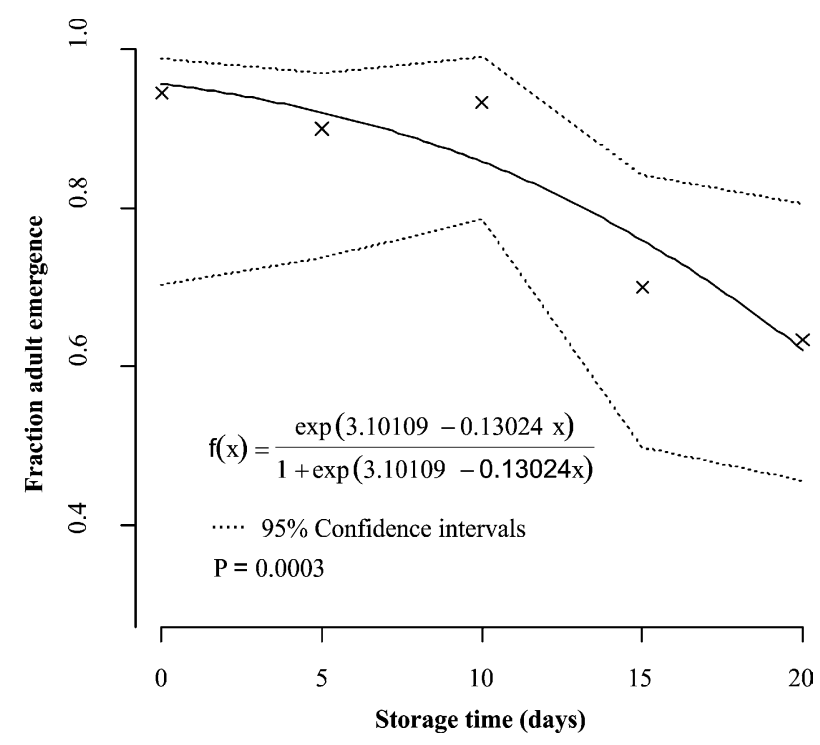

Fig. 1. Fraction of the mummies that produced adult Praon volucre recorded after storage for different periods of time at $5^{\circ} \mathrm{C}$, including the non-stored control mummies (day 0 ).

tion. We used the Wald Chi-Square to test for significance of effects of the models and parameters of the regression analyses. Data that met the assumptions of normality, homogeneity and independence were analyzed using ANOVA. One-way ANOVA and regression analyses were used to compare the size, the percentage of adults that flew, loss of mass $(\mathrm{mg})$ and fat content $(\mathrm{mg})$ of $P$. volucre kept for different periods at the low temperature. Two-way ANOVA was used to compare the longevity of male and female $P$. volucre stored for different periods. Sex of the parasitoid and length of the storage period were considered to be independent factors and the Tukey test was used to compare the longevity data. Two-way ANOVAs were also used to compare percentage parasitism and emergence of progeny, when the storage period and female age at time of parasitism are considered to be independent factors. Regression analysis was used for analyzing percentage parasitism after different periods of storage, while progeny emergence data were transformed using $\mathrm{y}=\arcsin [\operatorname{sqr}(\mathrm{x} / 100)]$ and averages were compared using the Tukey test. To determine the difference between a theoretical sex ratio of $1: 1$ and that observed, the data were analyzed using a homogeneity chi-square test $\left(\chi^{2}\right)$ with a 0.05 level of significance.

\section{RESULTS}

The longer the mummies of $P$. volucre were stored at $5^{\circ} \mathrm{C}$ the fewer adults that emerged $\left(\chi^{2}=143.72 ; \mathrm{df}=4 ; P\right.$ $<0.0001)$ and those that did were of a lower quality. Percentage adult emergence decreased with increase in time in storage $\left(\chi^{2}=13.08 ; \mathrm{df}=1 ; P=0.0003\right)$ (Fig. 1): in the control treatment the percentage emergence was $93.1 \%$, while it was $84.9 \%$ after 10 days of storage, $75.8 \%$ after 15 days and $63.5 \%$ after 20 days.

Dissection of mummies revealed that of the dead parasitoids in the mummies of the control treatment, 55.5\% were in the pre-pupal and $11.1 \%$ in pupal stages of development and $33.3 \%$ were adult. After storage for 5 days most of the dead parasitoids in the mummies were in the pre-pupal stage $(44.0 \%)$, as in the control treatment, while 


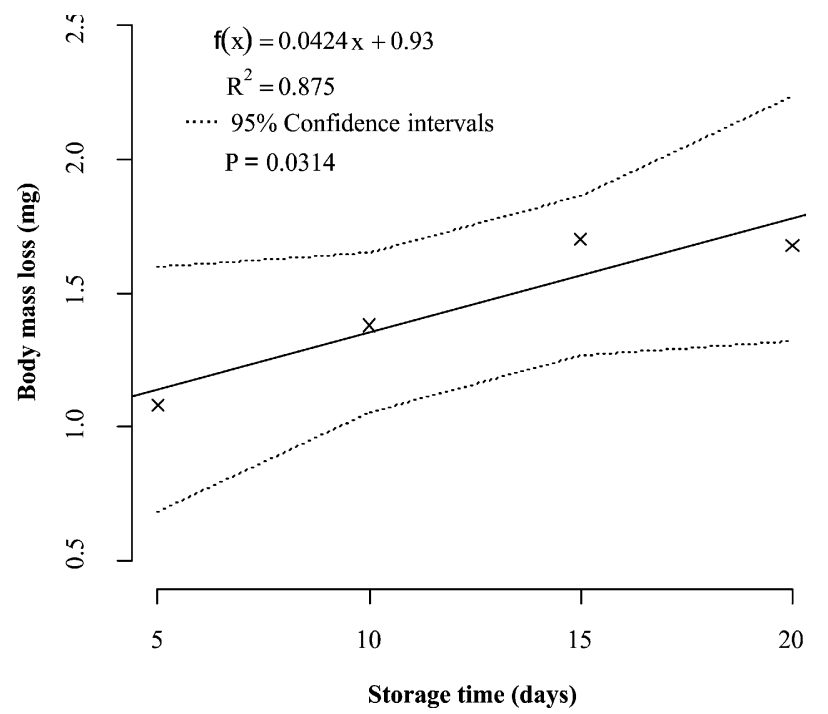

Fig. 2. The loss in body mass recorded for mummies of Praon volucre stored for different periods of time at $5^{\circ} \mathrm{C}$.

most dead parasitoids in the mummies stored for more than 5 days were adults (Table 1).

An increase in storage period led to a linear decrease in mass loss $(F=3.80 ; \mathrm{df}=3 ; P=0.0314)$ (Fig. 2$)$ and a linear decrease in fat content $(F=5.18 ; \mathrm{df}=4 ; P=$ 0.0050 ) (Fig. 3). The size of males and females of $P$. volucre expressed in terms of the length of the right tibia, was not affected by the length of the period in storage $(\delta$ : $F=2.45 ; \mathrm{df}=4 ; P=0.060 ;$ ㅇ $: F=2.21 ; \mathrm{df}=4 ; P=$ $0.0831)$. The average length of the right hind tibia was $0.6 \pm 0.013 \mathrm{~mm}$ for males and $0.68 \pm 0.018 \mathrm{~mm}$ for females. In terms of the longevity of $P$. volucre there was an interaction between the variables sex and storage period $(F=2.66 ; \mathrm{df}=4 ; P=0.0376)$. Longevity of $P$. volucre males was not affected by the period of storage $(F=0.55 ; \mathrm{df}=4 ; P=0.6991)$ (Table 2). Female longevity was affected by the period of storage $(F=3.50$; df $=4 ; P=0.0104)$; females developing from mummies kept for 15 days at $5^{\circ} \mathrm{C}$ lived longer than females developing from mummies stored for 20 days $(\mathrm{DMS}=5.31 ; P=$ $0.05)$. Longevity of males and females differed significantly $(F=12.74 ; \mathrm{df}=4 ; P=0.0006)$, although the females that emerged from mummies stored for 15 days lived significantly longer than the males (DMS $=3.79 ; P$ $=0.05)$.

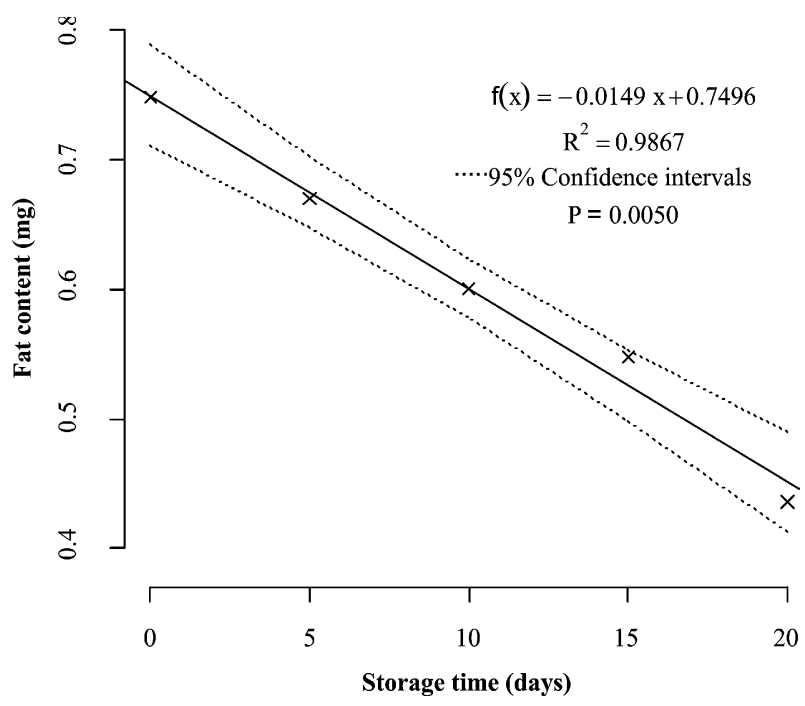

Fig. 3. The mass of fat recorded for mummies of Praon volucre stored for different periods of time at $5^{\circ} \mathrm{C}$, including the non-stored control mummies (day 0 ).

The percentage adults flying after the control treatment was $91.9 \%$ and decreased linearly with increasing length of the storage period to $66.3 \%$ after 20 days $(F=3.76$; df $=4 ; P=0.0195$ ) (Fig. 4).

The number of eggs in the ovarioles was affected by the length of the period in storage $\left(\chi^{2}=350.96\right.$; df $=4 ; P<$ $0.0001)$. The potential fecundity of $P$. volucre decreases with increase in the length of the period in storage $\left(\chi^{2}=\right.$ 25.70; df $=1 ; P<0.0001$ ) (Fig. 5). Females that emerged from mummies stored for 20 days had half of the number of eggs (84.8) of the control females (169.8).

For the percentage parasitism, we found no interaction between length of the period in storage and female age at time of parasitism $(F=0.38$; df $=8 ; P=0.9306)$. The percentage parasitism significantly decreased with increase in the length of the period in storage $(F=11.98$; df $=4 ; P<0.0001$ ) (Fig. 6). There were no significant differences in percentage of aphids parasitized by 24,48 and $72 \mathrm{~h}$-old females for any of the periods in storage $(F$ $=0.85 ; \mathrm{df}=2 ; P=0.4313$ ).

For the percentage emergence of female progeny, there was an interaction between period of storage and female age at time of parasitism $(F=4.30 ; \mathrm{df}=8 ; P=0.0001)$. While the percentage emergence was similar for control females and those that emerged from mummies stored for

TABLE 1. Percentage of dead parasitoids at different stages of development in mummies from which no adults emerged after storage at $5^{\circ} \mathrm{C}$ for different periods of time.

\begin{tabular}{cccc}
\hline \multirow{2}{*}{$\begin{array}{c}\text { Storage period } \\
\text { (days) }\end{array}$} & \multicolumn{3}{c}{ Percentage of dead parasitoids at different stages } \\
\cline { 2 - 4 } & Pre-pupae (n) & Pupa (n) & Adult (n) \\
\hline 0 & $55.5(5)$ & $11.1(1)$ & $33.3(3)$ \\
5 & $44.0(11)$ & $36.0(9)$ & $20.0(5)$ \\
10 & $20.0(4)$ & $30.0(6)$ & $50.0(10)$ \\
15 & $18.5(17)$ & $35.9(33)$ & $45.6(42)$ \\
20 & $16.0(17)$ & $39.6(42)$ & $44.33(47)$ \\
\hline
\end{tabular}

$\mathrm{n}$ - number of dead parasitoids recorded in each developmental stage. 
TABLE 2. Longevity ( \pm SE) of the adults of Praon volucre after storage of the mummies for different periods of time at $5^{\circ} \mathrm{C}$.

\begin{tabular}{ccc}
\hline \multirow{2}{*}{$\begin{array}{c}\text { Storage time } \\
\text { (days) }\end{array}$} & \multicolumn{2}{c}{ Longevity (days) } \\
\cline { 2 - 3 } & Males & Females \\
\hline 0 & $14.5 \pm 1.16 \mathrm{Aa}$ & $16.5 \pm 2.02 \mathrm{ABa}$ \\
5 & $16.2 \pm 1.14 \mathrm{Aa}$ & $16.9 \pm 1.22 \mathrm{ABa}$ \\
10 & $13.5 \pm 1.77 \mathrm{Ab}$ & $15.4 \pm 1.49 \mathrm{ABa}$ \\
15 & $15.3 \pm 1.24 \mathrm{Aa}$ & $20.3 \pm 1.05 \mathrm{Aa}$ \\
20 & & $14.7 \pm 0.73 \mathrm{Ba}$ \\
\hline
\end{tabular}

Averages followed by different capital letters in columns and different lower case letters in lines differ significantly by Tukey test $(P \leq 0.05)$.

5 days, the percentage emergence of progenies of females from mummies stored for 10, 15 and 20 days was significantly lower in several treatments (Table 3 ).

The length of the period of storage also affects the sex ratio of $P$. volucre (Table 4). Progeny from control females had a sex ratio of $1: 1$, independent of the age of the female when ovipositing $\left(24 \mathrm{~h}: \chi^{2}=0.2813, \mathrm{df}=1, P\right.$ $=0.65 ; 48 \mathrm{~h}: \chi^{2}=0.5912$, df $=1, P=0.49 ; 72 \mathrm{~h}: \chi^{2}=$ 0.1852 , $\mathrm{df}=1, P=0.73$ ). The sex ratios of the progenies of females from mummies stored for 5 days were slightly female biased. The sex ratios of progenies of 24 and 48 h-old females from mummies stored for 10,15 and 20 days tended to be male-biased and those of 72 h-old females to have a uniform sex ratio. The proportion of males was significantly higher in the progeny of $48 \mathrm{~h}$-old females after 10 days of storage $\left(\chi^{2}=13.7872\right.$, df $=1, P$ $<0.0001)$, and of 24 h-old females $\left(\chi^{2}=28.5882, \mathrm{df}=1\right.$, $P<0.0001)$ and 48 h-old females $\left(\chi^{2}=6.3684\right.$, df $=1, P$ $=0.016)$ after 20 days of storage.

\section{DISCUSSION}

In general, the magnitude of the harmful effects caused by storage at low temperatures is proportional to the

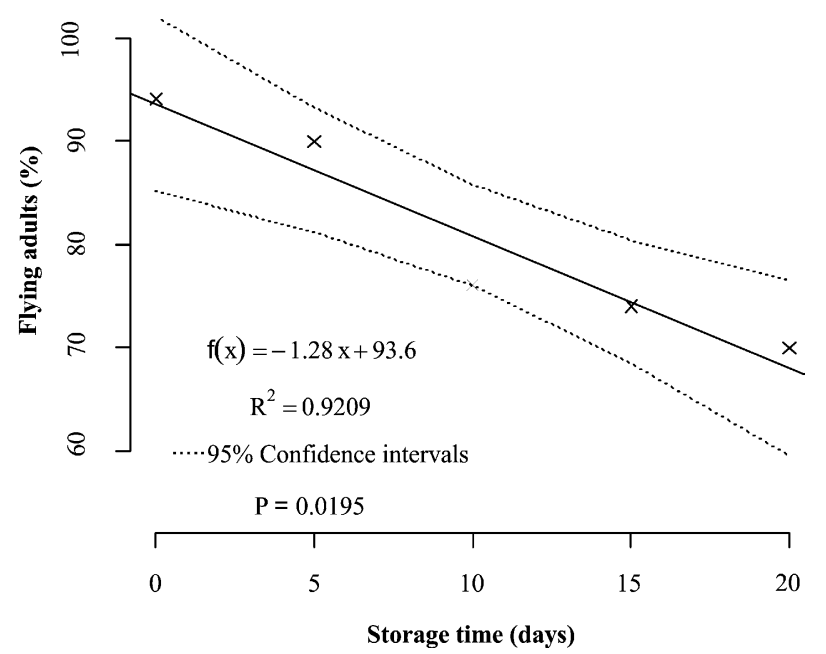

Fig. 4. Percentage of adult Praon volucre recorded flying after mummies were stored for different periods of time at $5^{\circ} \mathrm{C}$, including the non-stored control mummies (day 0).

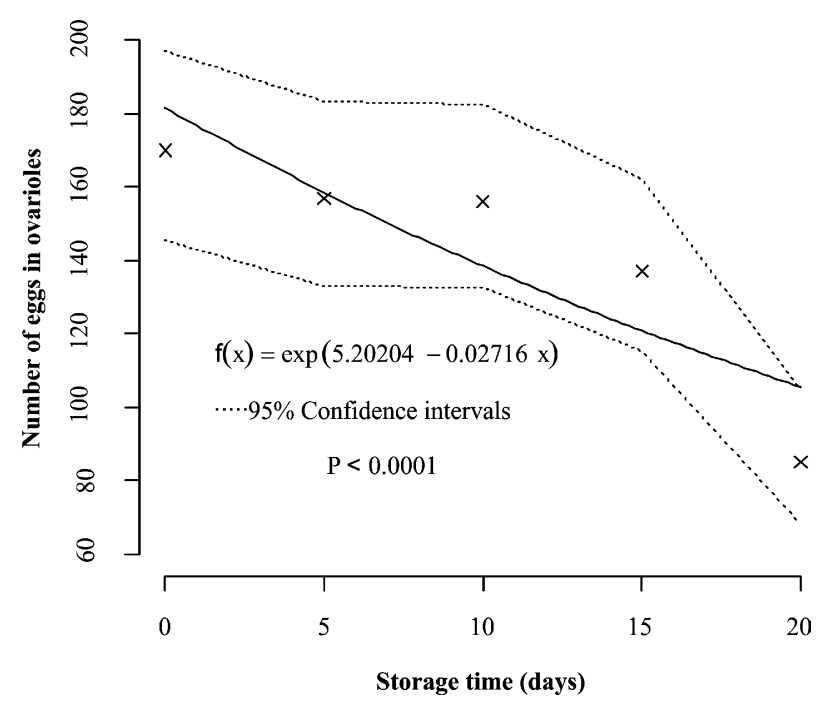

Fig. 5. The number of eggs recorded in ovarioles of $24 \mathrm{~h}$-old Praon volucre females that emerged from mummies stored for different periods of time at $5{ }^{\circ} \mathrm{C}$, including the non-stored control mummies (day 0).

length of the exposure (Leopld, 1998; Colinet \& Boivin, 2011). Although $P$. volucre is considered to be moderately tolerant of storage at low temperatures (Colinet \& Hance, 2010), the present study reveals that with increase in the period of storage there is an increase in the incidence of negative effects. Similar negative effects are recorded for other Aphidiinae parasitoids (Archer et al., 1973; Scopes et al., 1973; Hofsvang \& Hågvar, 1977; Singh \& Srivastava, 1988; Rodrigues et al., 2003; Colinet et al., 2006, 2007; Colinet \& Hance, 2010). In our experiments we used a pre-and post- acclimatization procedure, because it is supposed to reduce injuries caused by prolonged exposure to low temperatures (Leopold, 1998; Levie et al., 2005; Colinet \& Boivin, 2011). This may have contributed to the rather high percentages of $P$. volucre that emerged from mummies in all the treatments. In contrast, Rodrigues et al. (2003) record that only $7.5 \%$

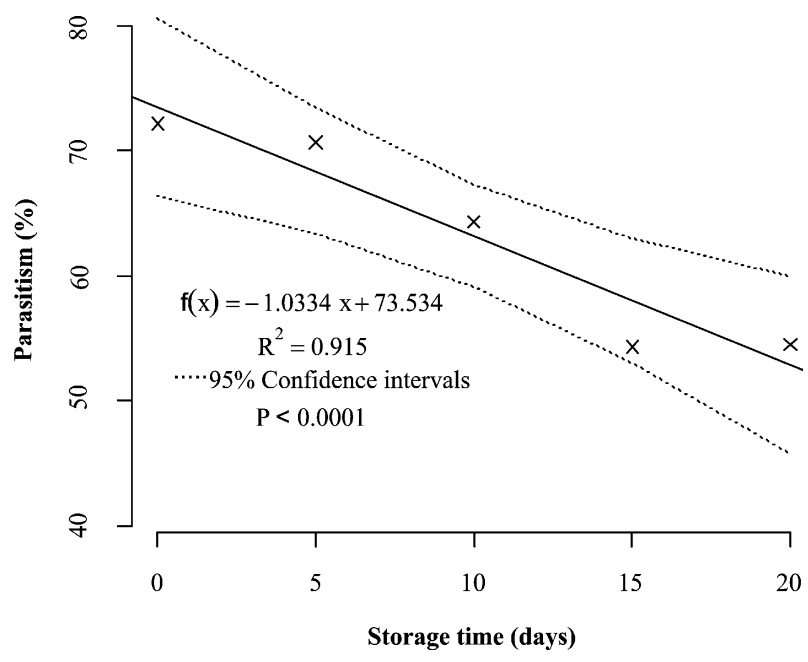

Fig. 6. Percentage of aphids parasitized ( \pm SE) by Praon volucre of different ages (24, 48 and $72 \mathrm{~h}$-old) after storage of mummies for different periods of time at $5^{\circ} \mathrm{C}$. 
TABLE 3. Percentage emergence ( \pm SE) of the offspring of 24 , 48 and 72 h-old Praon volucre that were stored as mummies for different periods of time at $5^{\circ} \mathrm{C}$.

\begin{tabular}{cccc}
\hline \multirow{2}{*}{$\begin{array}{c}\text { Storage time } \\
\text { (days) }\end{array}$} & \multicolumn{3}{c}{ Female age at time of parasitism } \\
\cline { 2 - 4 } & $24 \mathrm{~h}$ & $48 \mathrm{~h}$ & $72 \mathrm{~h}$ \\
\hline 0 & $72.5 \pm 2.72 \mathrm{Aa}$ & $79.3 \pm 2.53 \mathrm{Aa}$ & $77.5 \pm 2.64 \mathrm{Aa}$ \\
5 & $72.5 \pm 4.09 \mathrm{Aa}$ & $73.9 \pm 2.07 \mathrm{Aa}$ & $76.8 \pm 2.08 \mathrm{Aa}$ \\
10 & $46.1 \pm 5.67 \mathrm{Bb}$ & $58.2 \pm 4.76 \mathrm{Bab}$ & $65.4 \pm 5.91 \mathrm{ABa}$ \\
15 & $71.9 \pm 3.70 \mathrm{Aa}$ & $64.6 \pm 4.72 \mathrm{ABab}$ & $57.7 \pm 5.84 \mathrm{Bb}$ \\
20 & $76.1 \pm 3.52 \mathrm{Aa}$ & $56.8 \pm 4.01 \mathrm{Bb}$ & $69.77 \pm 4.23 \mathrm{ABa}$ \\
\hline
\end{tabular}

Averages followed by different capital letters in columns and different lowercase letters in lines differ significantly by Tukey test $(P \leq 0.05)$.

of the mummies of Lysiphlebus testaceipes (Cresson) (Hymenoptera: Braconidae) produced adults after being stored at $5^{\circ} \mathrm{C}$ for 20 days without acclimatization. Singh \& Srivastava (1988) record $40 \%$ adult emergence of Trioxys indicus Subba Rao \& Sharma (Hymenoptera: Braconidae) after 20 days of storage when the mummies were only subjected to pre-acclimatization. Following pre- and post-acclimatization $65 \%$ of the mummies of Aphidius colemani Viereck (Hymenoptera: Braconidae) produce adults after storage for 21 days at $4^{\circ} \mathrm{C}$ (Colinet et al., 2006), which is similar to that recorded here for $P$. volucre after storage for 20 days at $5^{\circ} \mathrm{C}$ and higher than the $40 \%$ recorded by Colinet \& Hance $(2010)$ when $P$. volucre is stored for 20 days at $2{ }^{\circ} \mathrm{C}$. Levie et al. (2005) report the effect of different methods of acclimatization on the percentage survival of the parasitoid Aphidius rhopalosiphi DeStefano-Peres (Hymenoptera: Braconidae) and show that regardless of the method used that the survival of mummies that were one day old when stored is greater than that of those that were stored when were three days old. Thus, it is clear that the age at which the mummies are stored is an important factor determining survival. We used one-day-old mummies in our experiments.

Cold hardiness is important in enabling parasitoids to survive when exposed to low temperatures (Langer \& Hance, 2000). The use of energy reserves by insects in a dormant stage is important because it determines the length of time they can survive (Denlinger \& Lee, 1998;
Sinclair et al., 2003). In our study, the mass of $P$. volucre mummies decreased with increase in the time they were stored at $5^{\circ} \mathrm{C}$. In particular, this reduction in mass is due to a high consumption of fat by parasitoids that are stored for a long time at low temperatures. Consumption of fat reserves results in a decrease in the fitness of the insects that emerge from dormancy, whether it is diapause or quiescence (Hahn \& Denlinger, 2007). We assume that the decrease in the fat reserves of $P$. volucre recorded affected key biological parameters, particularly percentage adult emergence, flight activity and fecundity. Colinet et al. $(2006,2007)$ also report a decrease in body mass with increase in the period of storage at low temperatures, which they attribute to the utilization of body biomass by the parasitoids. Dissection of mummies exposed to low temperatures from which no parasitoids emerged revealed that they mainly contained adult parasitoids. These dead adults apparently had insufficient energy to emerge from the mummy, as reported by Colinet et al. (2006) for $A$. colemani.

Prolonged exposure of immature parasitoids to low temperatures generally results in the adults living shorter (Hance et al., 2007). However, in our study the longevity of males of $P$. volucre was not affected by cold storage. The daily provisioning of $P$. volucre adults with honey and water may have resulted in the males and females that emerged from mummies stored for up to 15 days living for longer. According to Bueno et al. (2006), the supply of water and honey increases adult longevity in $A$. colemani. However, decreased longevity with increase in the period in storage is reported for the parasitoids Aphidius picipes Nees (Hymenoptera: Braconidae) (Amice et al., 2008) and A. colemani (Colinet et al., 2006), even when supplied daily with food.

Flight capacity is an important determinant of parasitoid performance under field conditions. Prolonged exposure to low temperatures often results in reduced flight capacity (van Lenteren \& Tommasini, 2003; Colinet \& Boivin, 2011). Interestingly, this study shows that the flight capacity of $P$. volucre remains high, even after 20 days of storage at $5^{\circ} \mathrm{C}$. Although the flight behaviour of Aphidiinae parasitoids has been studied (Guerrieri et al., 1993, 1999; Lo Pinto et al., 2004) and their flight capacity at low temperature determined (Langer et al.

TABLE 4. Sex ratio (expressed as proportion females) of the progeny of Praon volucre females that emerged from mummies stored at $5^{\circ} \mathrm{C}$ for different periods of time.

\begin{tabular}{|c|c|c|c|c|c|c|}
\hline \multirow{3}{*}{$\begin{array}{l}\text { Storage period } \\
\quad \text { (days) }\end{array}$} & \multicolumn{6}{|c|}{ Female age at time of parasitism } \\
\hline & \multicolumn{2}{|c|}{$24 \mathrm{~h}$} & \multicolumn{2}{|c|}{$48 \mathrm{~h}$} & \multicolumn{2}{|c|}{$72 \mathrm{~h}$} \\
\hline & $\mathrm{SR}\left(q \mid 0^{*}\right)^{*}$ & $\chi^{2}$ & $\mathrm{SR}(\stackrel{\uparrow}{0})$ & $\chi^{2}$ & 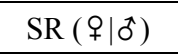 & $\chi^{2}$ \\
\hline 0 & $0.48(61 \mid 67)$ & $0.2813^{\mathrm{ns}}$ & $0.53(73 \mid 64)$ & $0.5912^{\text {ns }}$ & $0.52(70 \mid 65)$ & $0.1852^{\text {ns }}$ \\
\hline 5 & $0.56(71 \mid 55)$ & $2.0317^{\mathrm{ns}}$ & $0.64(84 \mid 47)$ & $10.4504 * *$ & $0.60(73 \mid 48)$ & $5.1653^{\text {ns }}$ \\
\hline 10 & $0.36(25 \mid 44)$ & $5.2319^{\mathrm{ns}}$ & $0.31(29 \mid 65)$ & $13.7872 * *$ & $0.54(51 \mid 43)$ & $0.6809^{\text {ns }}$ \\
\hline 15 & $0.42(39 \mid 54)$ & $2.4194^{\mathrm{ns}}$ & $0.60(51 \mid 34)$ & $3.4000^{\mathrm{ns}}$ & $0.59(44 \mid 30)$ & $2.6486^{\text {ns }}$ \\
\hline 20 & $0.24(24 \mid 78)$ & $28.5882 * *$ & $0.36(27 \mid 49)$ & $6.3684 * *$ & $0.62(57 \mid 35)$ & $5.2609^{\text {ns }}$ \\
\hline
\end{tabular}

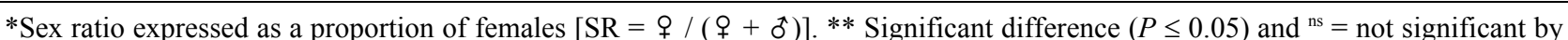
chi-square test; $\chi^{2}$ tabulated $=5.9915$. 
2004), there appears to be nothing published on the flight capacity of $P$. volucre after cold storage. Hahn \& Denlinger (2007) state that in many insects a prolonged dormancy may result in very high metabolic costs in maintaining the flight muscles in the immature stages, resulting in the adults having reduced flight capacity.

When parasitoids do not become dormant or are stored in cold conditions they can use most of their resources for reproduction (Ellers, 1996). Before emergence adult parasitoid can use resources to produce eggs in pro-ovigenic species, while in synovigenic species, like $P$. volucre, reserves accumulated during the larval stage can be used to produce supplementary eggs after emergence (Jervis et al., 2008). We observed a reduction in the number of eggs in $P$. volucre stored for a long period, which indicates that some of fat reserves must have been used while they were in storage. For egg formation, large amounts lipid are needed. When under stress, either nutrients are reallocated to sustain vital functions before egg formation, or already produced eggs are re-sorbed (Carbone et al., 2008), which reduces the reproductive potential of females (Bourdais et al., 2012). However, Petters \& Grosch (1977) report a rather different process: in the parasitoid Bracon hebetor Say (Hymenoptera: Braconidae) storage at a low temperature results in the production of supernumerary ovarioles and an increase in the reproductive potential of this parasitoid.

Ismail et al. (2010) found that male Aphidius ervi Haliday (Hymenoptera: Braconidae) parasitoids are more sensitive to cold storage than females, which indicates that cold affects the quality of sperm. We did not find any evidence of male sterility or high mortality of one of the sexes among the offspring of $P$. volucre that were stored at a low temperature. All the females produced female offspring, which indicates the males were fertile. But storage of $P$. volucre at a low temperature resulted in a male-biased sex ratio during the first two days of reproduction, while those that were not exposed to a cold temperature produced during the first three days of reproduction a constant proportion of males and females. The mechanism resulting in the changes in the sex ratio of $P$. volucre after storage have yet to be elucidated. Interestingly, Colinet \& Hance (2010) reports that $P$. volucre stored at a constant low temperature and under fluctuating thermal regimes have male-biased sex ratios (approximately $70 \%$ males).

Our results indicate that $P$. volucre can be stored 5 days at $5^{\circ} \mathrm{C}$ without any loss of quality, and up to 10 days with some loss of quality (lower flight activity, lower percentage emergence of progeny and a slightly male-biased sex ratio). When stored for longer than 10 days the quality of the parasitoids is more adversely affected. Thus, short cold storage periods associated with a pre-and post- acclimatization method can be used to facilitate the planning of the mass production and shipment of this parasitoid.

ACKNOWLEDGEMENTS. We thank the Conselho Nacional de Desenvolvimento Científico e Tecnológico (CNPq) and the
Fundação de Amparo à Pesquisa do Estado de Minas Gerais (FAPEMIG) for financial support.

\section{REFERENCES}

Amice G., Vernon P., Outreman Y., Alphen J. van \& Bahen J. VAN 2008: Variability in responses to thermal stress in parasitoids. - Ecol. Entomol. 33: 701-708.

Archer T.L., Murray C.L., Eikenbary R.D., Starks K.J. \& Morrison R.D. 1973: Cold storage of Lysiphlebus testaceipes mummies. - Environ. Entomol. 2: 1104-1108.

Bourdais D., Vernon P., Krespi L. \& BaAren J. van 2011: Behavioural consequences of cold exposure on males and females of Aphidius rhopalosiphi De Stephani Perez (Hymenoptera: Braconidae). - BioControl 57: 349-360.

Bueno V.H.P., Sampaio M.V., Lenteren J.C. van, De Conti B.F., Silva R.J., Rodrigues S.M.M. \& Carnevale A.B. 2006: Evaluation of two aphid parasitoid as candidates for biological control of aphids in protected cultivation in Brazil. IOBC/WPRS Bull. 29: 175-180.

Carbone S.S., Nieto M.P. \& Rivera A.C. 2008: Egg resorption behaviour by the solitary egg parasitoid Anaphes nitens under natural conditions. - Entomol. Exp. Appl. 127: 191-198.

Carver M. \& Woolcock L.T. 1986: The introduction into Australia of biological control agents of Hyperomyzus lactucae (L.) (Homoptera: Aphididae). - Aust. J. Entomol. 25: 65-69.

Colinet H. \& Boivin G. 2011: Insect parasitoids cold storage: A comprehensive review of factors of variability and consequences. - Biol. Control. 58: 83-95.

Colinet H. \& Hance T. 2010: Interspecific variation in the response to low temperature storage in different aphid parasitoids. - Ann. Appl. Biol. 156: 147-156.

Colinet H., Hance T. \& Vernon P. 2006: Water relations, fat reserves, survival, and longevity of a cold-exposed parasitic wasp Aphidius colemani (Hymenoptera: Aphidiinae). - Environ. Entomol. 35: 228-236.

Colinet H., Vernon P. \& Hance T. 2007: Does thermal-related plasticity in size and fat reserves influence supercooling abilities and cold-tolerance in Aphidius colemani (Hymenoptera: Aphidiinae) mummies? - J. Therm. Biol. 32: 374-382.

De Conti B.F., Bueno V.H.P. \& Sampaio M.V. 2008: The parasitoid Praon volucre (Hymenoptera: Braconidae: Aphidiinae) as a potential biological control agent of the aphid Uroleucon ambrosiae (Hemiptera: Aphididae) on lettuce in Brazil. Eur. J. Entomol. 105: 485-487.

De Conti B.F., Bueno V.H.P. \& Sampaio M.V. 2010: Reproduction and fertility table life of three aphids species (Macrosiphini) at different temperatures. - Rev. Bras. Entomol. 54: 654-600.

De Conti B.F., Bueno V.H.P., Sampaio M.V. \& Lenteren J.C. VAN 2011: Biological parameters and thermal requirements of the parasitoid Praon volucre (Hymenoptera: Braconidae) with Macrosiphum euphorbiae (Hemiptera: Aphididae) as host. Biocontr. Sci. Technol. 21: 497-507.

Denlinger D.L. \& Lee R.E. JR. 1998: Physiology of cold sensitivity. In Hallman G.L. \& Denlinger D.L. (eds): Temperature Sensitivity in Insects and Application in Integrated Pest Management. Westview Press, Boulder, CO, pp. 55-96.

ELLERS J. 1996: Fat and eggs: an alternative method to measure the tread-of between survival and reproduction in insects parasitoids. - Neth. J. Zool. 46: 227-235.

GASSEN D.N. \& TAMBASCo F.J. 1983: Biological control of aphids in wheat in Brazil. Inf. Agropec. 9: 49-51 [in Portuguese].

Gerrieri E., Pennacchio F. \& Tremblay E. 1993: Flight behavior of the aphid parasitoid Aphidius ervi (Hymenoptera: 
Braconidae) in response to plant and host volatiles. - Eur. $J$ Entomol. 90: 415-421.

Guerrieri E., Poppy G.M., Powell W., Tremblay E. \& PennacCHIO F. 1999: Induction and systemics releases of herbivoreinduced plant volatiles mediating in-flight orientation of Aphidius ervi. - J. Chem. Ecol. 25: 1247-1261.

Gujarati D.N. 2004: Basic Ecomometrics. McGraw Hill, New York, NY, 1002 pp.

Hahn D.A. \& Denlinger D.L. 2007: Meeting the energetic demands of insect diapause: nutrient storage and utilization. - J. Insect Physiol. 53: 760-773.

Hance T., BaAren J. van, Vernon P. \& Boivin G. 2007: Impact of extreme temperatures on parasitoids in a climate change perspective. - Annu. Rev. Entomol. 52: 107-126.

Hofsvang T. \& HÅgvar E.B. 1977: Cold storage and supercooling points of mummies of Ephedrus cerasicola Starý and Aphidius colemani Viereck (Hym. Aphidiidae). - Norw. J. Entomol. 24: 1-6.

Ismail M., Vernon P., Hance T. \& BaAren J. van 2010: Physiological costs of cold exposure on the parasitoid Aphidius ervi, without selection pressure and under constant or fluctuating temperatures. - BioContr. 55: 729-740.

Jervis M.A., Ellers J. \& Harvey J.A. 2008: Resource acquisition, allocation, and utilization in parasitoid reproductive strategies. - Annu. Rev. Entomol. 53: 361-385.

LANGER A. \& HANCE T. 2000: Overwintering strategies and cold hardiness of two aphid parasitoid species (Hymenoptera: Braconidae: Aphidiinae). - J. Insect Physiol. 46: 671-676.

Langer A., Boivin G. \& Hance T. 2004: Oviposition, flight and walking capacity at low temperatures of four aphid parasitoid species (Hymenoptera: Aphidiinae). - Eur. J. Entomol. 101: 473-479.

Lee Y., Nelder J.A. \& Pawitan Y. 2006: Generalized Linear Models with Random Effects. Chapman \& Hall, New York, NY, 416 pp.

LENTEREN J.C. VAN 2011: The state of commercial augmentative biological control: plenty of natural enemies, but a frustrating lack of uptake. - BioControl 57: 1-20.

Lenteren J.C. van \& Tommasini M.G. 2003: Mass production, storage, shipment and release of natural enemies. In Lenteren J.C. van (ed.): Quality Control and Production of Biological Control Agents: Theory and Testing Procedures. CABI, Wallingford, pp. 181-190.

Lenteren J.C. van, Hale A., KlapwiJk J.N., Schelt J. van \& Steinberg S. 2003: Guidelines for quality control of commercially produced natural enemies. In Lenteren J.C. van (ed.): Quality Control and Production of Biological Control Agents: Theory and Testing Procedures. CABI, Wallingford, pp. 265-304.

LEOPOLD R.A. 1998: Cold storage of insects for integrated pest management. In Hallman G.L. \& Denlinger D.L. (eds): Temperature Sensitivity in Insects and Application in Integrated Pest Management. Westview Press, Boulder, CO, pp. 235-267.

Levie A., Vernon P. \& Hance T. 2005: Consequences of acclimation on survival and reproductive capacities of cold-stored mummies of Aphidius rhopalosiphi (Hymenoptera: Aphidiinae). - J. Econ. Entomol. 98: 704-708.

Lins J.C. JR., Bueno V.H.P., Silva D.B., Sampaio M.V. \& LenTEREN J.C. VAN 2011: Praon volucre (Hymenoptera: Braconidae, Aphidiinae), a natural enemy of Macrosiphum euphorbiae (Hemiptera: Aphididae): life table and intrinsic rate of population increase. - Eur. J. Entomol. 108: 575-580.

Lo Pinto M., Wajnberg E., Colazza S., Curty C. \& Fauvergue X. 2004: Olfactory response of two aphid parasitoids, Lysi- phlebus testaceipes and Aphidius colemani, to aphid-infested plants from a distance. - Entomol. Exp. Appl. 110: 159-164.

McCullagh P. \& Nelder J.A. 1989: Generalized Linear Models. Chapman \& Hall, London, 532 pp.

Nelder J.A. \& Wedderburn R.W.M. 1972: Generalized Linear Models. - J. Roy. Statist. Soc. (A) 135: 370-384.

PeÑA-Martinez R. 1992: Identification of aphids of agricultural importance. In Urias M.C., Rodriguez M.R. \& Alejandre A.T. (eds): Aphids as Vectors of Virus in Mexico. Centro de Fitopatologia, Montecillo, MS, pp. 1-135 [in Spanish].

PetTers R.M. \& Grosch D.S. 1977: Reproductive performance of Bracon hebetor females with more or fewer than normal number of ovarioles. - Ann. Entomol. Soc. Am. 70: 577-582.

R Development Core Team 2008: A Language and Environment for Statistical Computing. Institute for Statistics and Mathematics of the University of Wien, http://www.R-project.org.

Rodrigues S.M.M., Bueno V.H.P. \& SAMPAio M.V. 2003: Storage of mummies of Schizaphis graminum (Rondani) (Hemiptera: Aphididae) parasitized by Lysiplhebus testaeipes (Cresson) (Hymenoptera: Aphidiidae) in low temperature. Bol. Sanid. Veg. Plagas 29: 367-374 [in Portuguese].

Sampaio M.V., Bueno V.H.P. \& De Conti B.F. 2008: The effect of the quality and size of host aphid species on the biological characteristics of Aphidius colemani (Hymenoptera: Braconidae: Aphidiinae). - Eur. J. Entomol. 105: 489-494.

Scopes N.E.A., Biggerstaff S.M. \& Goodall D.E. 1973: Cold storage of same parasites used for pest control in glasshouses. - Plant Pathol. 22: 189-193.

Sidney L.A., Bueno V.H.P., Lins J.C. JR, Silva D.B. \& Sampaio M.V. 2010: Quality of different aphids species as hosts for the parasitoid Aphidius ervi Haliday (Hymenoptera: Braconidae: Aphidiinae). - Neotrop. Entomol. 39: 709-713 [in Portuguese].

Silva D.B., Bueno V.H.P., Lins J.C. JR, Sidney L.A. \& CarVALHO A.R. 2009: Quality of the aphid Aulacorthum solani for the parasitoid Praon volucre. - IOBC/WPRS Bull. 49: 267-271.

Sinclair B.J., Vernon P., KloK C.J. \& Chown S.L. 2003: Insects at low temperatures: an ecological perspective. Trends Ecol. Evol. 18: 257-262.

Singh S. \& SRIVASTAVA M. 1988: Efect of cold storage of mummies of Aphis craccivora Koch subjected to different prestorage temperature on per cent emergence of Trioxys indicus Subba Rao \& Sharma. - Insect Sci. Appl. 9: 635-657.

Starý P., Sampaio M.V. \& Bueno V.H.P. 2007: Aphid parasitoids (Hymenoptera, Braconidae, Aphidiinae) and their associations related to biological control in Brazil. - Rev. Bras. Entomol. 51: 107-118.

Tezze A.A. \& BotTo E.N. 2004: Effect of cold storage on the quality of Trichogramma nerudai (Hymenoptera: Trichogrammatidae). - Biol. Contr. 30: 11-16.

Tomanović Ž.E., Kavallieratos N.G., Athanassiou C.G. \& Stanisavlević L.C. 2003: A review of the West Palaearctic aphidiines (Hymenoptera: Braconidae: Aphidiinae) parasitic on Uroleucon sp., with the description of a new species. Ann. Soc. Entomol. Fr. 39: 343-353.

Tomanović Ž.E., Kavallieratos N.G., Starý P., Stanisavluević L.Ž., Ćetković A., Stamenković S., Jovanović S. \& AthanasSIOU C.G. 2009: Regional tritrophic relationship patterns of five aphid parasitoid species (Hymenoptera: Braconidae: Aphidiinae) in agroecosystem-dominated landscapes of Southeastern Europe. - J. Econ. Entomol. 102: 836-854.

Received August 15, 2012; revised and accepted October 23, 2012 